\title{
RÉPLICA A: «SOBRE DILEMAS EDUCATIVOS EN EL SIGLO XIX Y LA CONTROVERSIA PARA SELECCIONAR LOS LIBROS DE LÓGICA EN EL CURRÍCULO», DE VIRGINIA ASPE ARMELLA
}

\section{EL DILEMA DE LA EDUCACIÓN LIBERAL}

El trabajo de Virginia Aspe da pistas para rastrear el dilema de fondo en la configuración de la educación pública mexicana desde mediados del siglo XIX: cómo implementar la modernización educativa. Para ello se ocupa de un tema preocupante: la controversia en torno al plan o programa de estudios de la lógica en el nivel bachillerato y, para entenderlo, nos propone repasar la historia del contexto de nuestros programas de estudio. Asumiendo el riesgo de ser reiterativo, quisiera referirme a tres detalles que resalta con su trabajo.

Primero, recordar que la tradición educativa novohispana giraba alrededor del escolasticismo que se profesaba en la Real y Pontificia Universidad de México y en los centros de estudios promovidos por las diversas órdenes religiosas, y trataba (aunque es discutible decidir 
qué tan exitosamente) de seguir los lineamientos del Concilio de Trento en la enseñanza de Santo Tomás de Aquino, con múltiples variaciones escotistas y suarecianas, y algunas adiciones de filosofía moderna importadas sobre todo de Francia.

Segundo, es probable que la mayoría de los primeros políticos mexicanos, monárquicos o republicanos, no hayan pensado en desmantelar las instituciones vigentes, incluidas las educativas; en concreto, es cierto que las constituciones republicanas de 1824 y 1836 insistieron en conservar la católica romana como la religión de Estado. Así pues, parece que los relativamente pocos republicanos mexicanos que profesaban cierto liberalismo político y económico antes de 1850 (notablemente, José María Luis Mora y Valentín Gómez Farías), no lograron reflejar sus ideas en las primeras constituciones de México.

Esta distinción entre liberalismos «político» $\mathrm{y}$ «económico» requiere una breve digresión. Entendamos como «liberalismo» a la doctrina que enfatiza la importancia de las libertades como derechos fundamentales de los ciudadanos. Ambos «liberalismos» —el político y el económicoenfatizan en particular las libertades de intercambio; pero mientras la versión «política» enfatiza, como parte de los derechos políticos, la libertad en el intercambio de ideas, y termina defendiendo las libertades de conciencia y expresión, y como consecuencia de ellas, la libertad de cultos, la versión «económica» enfatiza la libertad en el intercambio de bienes tangibles, particularmente los bienes inmobiliarios, y rechaza como consecuencia las formas corporativas o intocables de propiedad de estos bienes; esto incluía, a principios del siglo XIX, tanto las propiedades eclesiásticas como las tierras comunales indígenas. Estos liberalismos -económico y político- cristalizaron en la Constitución de 1857 y las Leyes de Reforma de 1858-1861, pero no surtieron efecto real hasta después del triunfo republicano contra la Intervención Francesa y el Segundo Imperio en 1867.

Tercero, y es en este contexto en que debe entenderse el trabajo de Aspe, los efectos inmediatos de la victoria republicana liberal fueron la clausura permanente de la Pontificia Universidad de México y el desconocimiento de los estudios realizados en los conventos, y como consecuencia, el atrincheramiento del escolasticismo en los seminarios diocesanos y las órdenes religiosas de México, y la necesidad de los 
gobiernos republicanos de sustituirlos con instituciones nuevas, en concreto con la fundación de las Escuelas Nacionales Preparatoria y de Jurisprudencia, Medicina y Minería.

Es en este periodo donde aparece el problema que documenta el trabajo de Aspe: cómo implementar la modernización educativa. Efectivamente, en el terreno de la libertad de ideas, que es el que ocupa a Aspe, los liberales mexicanos se vieron en un predicamento: al principio no había que defender ningún pluralismo de opiniones, simplemente porque no existía; y en consecuencia, parecía que la tarea del Estado consistía entonces en promoverlo. Pero así como al tratar de promover las libertades económicas, los liberales adoptaron medios que terminaron desposeyendo a los trabajadores de tierras comunes, en la práctica, los intentos modernizadores quedaron en manos de positivistas ideológicos, como Gabino Barreda y los «científicos», por encima de personas con ideales liberales clásicos, como Ignacio Mariscal. No daré más detalles del conflicto histórico que documenta Aspe; solo subrayo la tensión interna entre bandos liberales, en que el liberal clásico Mariscal intenta prescribir un libro de texto con aspiraciones espirituales, aunque aconfesionales, para dar espacio a la libertad religiosa garantizada por la Constitución de 1857, y enfrenta a la oposición de los responsables de la naciente educación pública en nombre del progreso científico predicado por la filosofía positivista.

Para terminar, quisiera servirme de la presentación de este conflicto para tratar de aplicarla a nuestra problemática actual.

Un problema fundamental del liberalismo político, y esto reaparece, me parece, en el trabajo de John Rawls, es que los ideales liberales fácilmente se convierten en una doctrina comprehensiva ultra-mínima, parafraseando a Robert Nozick. En otras palabras: encontramos la paradoja liberal de que, para promover la diversidad, hace falta una decisiva intervención estatal, que es precisamente una de las cosas que rechazaría un liberal consecuente. La alternativa es negar en redondo que intentamos promover una república liberal pluralista; pero entonces habría que reconocer sinceramente que solo se trata de reemplazar el comunitarismo tradicional con uno distinto: «moderno». El problema general es que es muy difícil promover el liberalismo político en 
culturas tradicionales homogéneas sin prescribir indirectamente las divisiones inherentes al «liberalismo occidental», minando las culturas originales, como vemos que ha ocurrido en diversas partes del globo.

Como profesor de lógica, me habría encantado que Aspe descendiera a más detalles de la divergencia entre los programas de Tiberghien y Stuart Mill, de Mariscal y los positivistas respectivamente, así que espero sinceramente una continuación de este trabajo.

José Luis Rivera $N$. 